\title{
Questões metodológicas sobre a acomodação fonológica na música popular
}

\section{Methodological questions regarding phonological accommodation in popular music}

\author{
André Luiz Machado ${ }^{1}$ \\ Gladis Massini-Cagliari ${ }^{2}$
}

\begin{abstract}
Resumo: Além de uma forma de transmitir significados de um falante para um ouvinte, a língua é também um meio pelo qual a idade, o gênero, a classe social, e a origem geográfica - enfim, a identidade - dos falantes se manifestam. Os falantes têm consciência disso e, ocasionalmente, manipulam seus marcadores linguísticos com fins estilísticos e retóricos. No campo da música popular, já se fala, há algumas décadas, sobre a mudança na pronúncia dos intérpretes, em uma tensão entre manifestação de identidade e acomodação a expectativas estilísticas e sociais, sendo o trabalho de Peter Trudgill (1983) um dos exemplos mais célebres. Neste artigo, argumentamos que qualquer estudo com intenção de explorar esse fenômeno deve tomar especial cuidado em relação às descrições dos dialetos linguísticos em questão, sob o risco de distorcer profundamente os resultados. Mostramos também como a análise da fala do intérprete, ao lado da análise da pronúncia na música, pode nos ajudar a chegar a interpretações menos óbvias dos dados colhidos. Para tanto, analisamos um corpus composto de canções de artistas que têm pouco em comum - a cantora brasileira Rita Lee e o grupo vocal britânico Spice Girls - bem como amostras de fala espontânea das intérpretes.
\end{abstract}

Palavras-chave: Fonoestilística. Sotaque. Música popular. Pronúncia.

Abstract: More than a means of transmitting messages from a speaker to a listener, the language is also a means through which a speaker's age, gender, social class and geographical origin - in other words, their identity - manifest. Speakers are aware of this and, occasionally, manipulate linguistic markers with stylistic and rhetorical ends. In popular music, the change in performers' pronunciation and the tension between identity manifestation and accommodation to social and stylistic expectations has been a subject for some decades, the work of Peter Trudgill (1983) being one of the best-known examples. In this paper, we posit that any study aiming to explore such phenomenon must be especially careful regarding the description of the linguistic dialects in question, to avoid the risk of distorting the results deeply. We also show how analysing the performer's speech, in addition to the pronunciation in song, may help us reach less obvious interpretations of the data collected. In order to do that, we analysed a corpus composed of songs by artist who have little in common - the Brazilian singer Rita Lee and the British vocal group Spice Girls - as well as spontaneous speech samples of the performers.

Keywords: Phonostylistics. Accent. Popular music. Pronunciation.

\footnotetext{
1 Universidade Estadual Paulista "Júlio de Mesquita Filho", Faculdade de Ciências e Letras de Araraquara, Programa de Pós-Graduação em Linguística e Língua Portuguesa, Araraquara, SP, Brasil. Endereço eletrônico: andre.machado@unesp.br.

${ }^{2}$ Universidade Estadual Paulista "Júlio de Mesquita Filho", Faculdade de Ciências e Letras de Araraquara, Programa de Pós-Graduação em Linguística e Língua Portuguesa, Araraquara, SP, Brasil. Endereço eletrônico: gladis.massini-cagliari@unesp.br. CNPq (Processo: 302648/2019-4).
} 


\section{Introdução}

Existe, entre os falantes de inglês, uma percepção de que alguns intérpretes, especialmente os britânicos, reduzem ou perdem totalmente seu sotaque quando cantam. De fato, se digitarmos "Why do British"3 no serviço de buscas online Google, o mecanismo de busca nos sugerirá algumas das questões mais comumente buscadas no serviço. Além de questões factuais como "dirigir do lado esquerdo" e estereótipos como "ter dentes amarelos", notaremos que uma pergunta bastante comum é "Why do British singers sound American?" (em tradução livre: “por que cantores britânicos soam como americanos?”).

Figura 1 - Captura do site Google quando o usuário digita o texto "Why do British" no campo de busca.

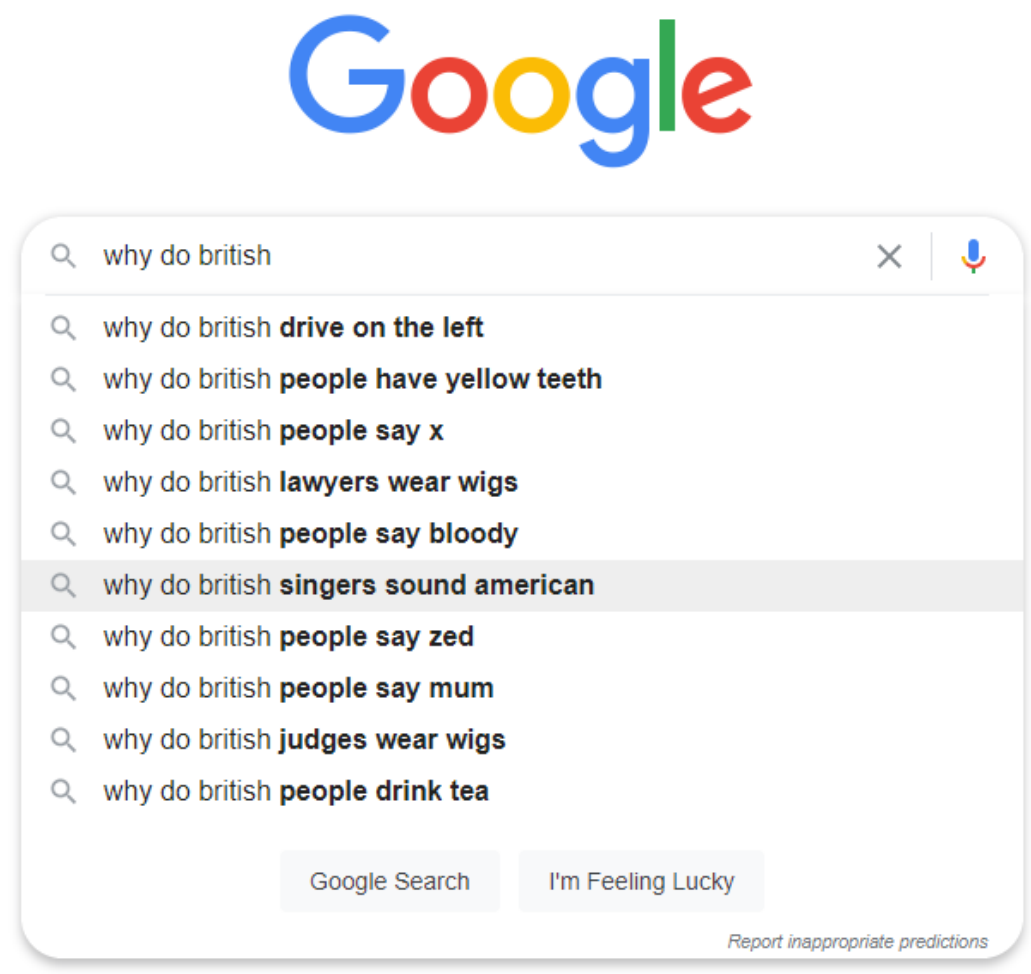

Fonte: Google (https://www.google.com/), capturado em 27 mar. 2021.

A noção de que intérpretes britânicos "perdem o sotaque" ou mesmo soam americanos ao cantar não é nova nem restrita. Diversos artigos e discussões em fóruns na internet já se debruçaram, de forma predominantemente anedótica e não-científica, sobre essa questão (ADAMS, 2017, HONEYCUTT, 2013, VARAH, 2019). Em linhas gerais, as explicações oferecidas parecem remeter de forma indireta a Peter Trudgill e de forma direta a David Crystal, ambos linguistas britânicos. No caso de Crystal, a fonte parece ser uma entrada no blog do autor (CRYSTAL, 2009), em que o linguista reconhece a suavização de sotaques regionais em

\footnotetext{
${ }^{3}$ Por que britânicos...?
} 
interpretações cantadas. Como razões para tal fenômeno, Crystal elenca como primeiramente o fato de que a melodia e o ritmo de uma composição musical se sobrepõem a, ou até mesmo restringem, entonação e ritmo linguístico, neutralizando dois dos aspectos mais marcantes de um sotaque. Crystal também menciona a acomodação do sotaque à variedade associada com prestígio social e/ou à origem do gênero musical do intérprete, na mesma linha do proposto por Peter Trudgill (1983).

\section{Em Acts of Conflicting Identity: The Sociolinguistics of British Pop-song} Pronunciation, Peter Trudgill (1983, p. 254) argumenta que, tanto quanto ou mais do que às limitações impostas por padrões estruturais da canção, a mudança de dialeto percebida em intérpretes britânicos se deve às origens dos gêneros musicais em que esses intérpretes se inserem: considerando que a maioria dos gêneros de música popular do século 20 têm origem afro-americana, internaliza-se a noção de que é apropriado soar americano em um gênero cujas referências são justamente artistas americanos (TRUDGILL, 1983, p. 254). Essa noção levaria intérpretes britânicos a emularem características estereotipicamente "americanas". Trudgill também tenta reforçar sua argumentação lembrando a presença frequente de palavras como guy, então consideradas americanismos, mesmo em composições de britânicos destinadas ao mercado doméstico. Em que pese a evidência de uma influência americana na música, o aspecto lexical não será abordado neste trabalho, uma vez que empréstimos lexicais e estrangeirismos costumam ser adaptados ao sistema fonológico da língua, e não o contrário (nesse sentido, ver ASSIS, 2007, por exemplo). Também optamos por desconsiderar a variação prosódica e nos deter ao domínio segmental, uma vez que estabelecer os limites de influência e negociação entre prosódia e ritmo linguístico e melodia e ritmo musical aumentaria excessivamente o escopo da empreitada aqui apresentada ${ }^{4}$.

\footnotetext{
${ }^{4}$ Apesar de, neste artigo, optarmos por focalizar o nível segmental, trabalhos como Massini-Cagliari, (2008, 2010, 2011a) e Costa (2010), que analisaram cantigas medievais galego-portuguesas profanas e religiosas, objetivaram investigar como a relação entre letra e música pode contribuir para a caracterização da prosódia, uma vez que as músicas cantadas se baseiam em uma relação entre os níveis musical e linguístico, mediada pelo nível poético, mostrando que proeminências musicais combinam-se prioritariamente com proeminências linguísticas, trazendo pistas do acento e do ritmo na oralidade da época. Sobre essa possibilidade de combinação (proposital?) entre prosódia musical e linguística, Chico Buarque de Holanda comenta explicitamente sobre a maneira como age, com relação à combinação de acentos musicais e linguísticos, na Coleção de DVDs Chico: A série, no DVD1 (Meu caro amigo. RWR Comunicações Ltda, EMI Music Brasil Ltda, 2006), deixando clara que a tendência a combinar proeminências musicais e linguísticas pode já estar na gênese do ato de composição, em casos específicos: "A letra que você faz para a música, você tem que fazer para aquela música que já existe, que já tem uma forma fixa. Você não pode alterar nada. As pessoas falam isso, comparam muito com poesia; não tem nada a ver, é outra coisa. Mas é muito mais difícil, porque você tem que fazer aquela letra, respeitando cada nota, a métrica, que não é exatamente a mesma coisa que fazer uma fórmula fixa de um soneto, não, não é uma fórmula fixa. Cada frase é de um tamanho diferente. Você tem que respeitar a prosódia musical, ou seja, a letra, a tônica das palavras coincidir com a tônica da música. Ou desrespeitar a prosódia de propósito e tal; e tudo isso, e, no fim, e rimas, e rimas, e, no fim, ainda fazer algum sentido, de preferência, ficar uma coisa interessante ou bonita de se ouvir".
} 
No tocante ao Português Brasileiro, até onde pudemos constatar, as reflexões sobre a pronúncia na música não abordaram questões de fonoestilística relacionadas à identidade ou a acomodação fonológica em um padrão relacionado a gêneros específicos, como feito por Peter Trudgill em relação ao inglês. No entanto, julgamos importante que questões já abordadas em outros idiomas sejam investigadas também no português. Assim, decidimos apresentar também uma investigação da pronúncia na música popular de um intérprete brasileiro.

Em ambos os casos, o que está em questão é a manifestação da identidade fonológica, um aspecto da identidade linguística dos falantes. Aqui, entendemos identidade linguística como "o conjunto de características que identificam a língua(gem) de uma pessoa ou de um grupo que possui características semelhantes" na definição sucinta de Rostas (2010, p. 22). No nível fonológico, essa identidade se manifesta tanto no nível segmental (os alofones usados para pronunciar determinado fonema, processos de neutralização, etc.) quanto suprassegmental (ritmo, padrões entoacionais, etc). Esses marcadores fonológicos permitem a identificação e divisão de/em grupos linguísticos (e, por extensão, sócio-identitários) distintos:

\footnotetext{
A partir dessa identificação, é possível perceber que o falante adota ou deixa de adotar certos padrões para marcar uma atitude de inclusão/exclusão, com relação a uma comunidade linguística específica. [...] do ponto de vista fonológico, pode-se dizer que essa identificação se manifesta através da forma como o falante pronuncia as palavras consciente ou inconscientemente de forma mais ou menos semelhante aos membros de sua comunidade. (MASSINI-CAGLIARI, 2011b, p. 796)
}

Para retomar o trabalho de Trudgill (1983), quando um intérprete britânico adota uma pronúncia característica de uma - suposta - variedade norte-americana, tem-se um movimento no qual o intérprete deixa de adotar padrões de sua comunidade original, desprendendo-se dela, e os substitui por outros, numa tentativa de se incluir nesse outro grupo, que pode ser o dos integrantes da tradição e do cânone do gênero musical em questão, o público-alvo que o artista deseja atingir com sua obra, ou ambos.

\section{Metodologia}

O corpus deste trabalho é composto de dez canções interpretadas por artistas que têm pouco em comum: a cantora e compositora brasileira Rita Lee e o grupo vocal feminino inglês Spice Girls. Apesar de apelarem para públicos bastante diferentes, cantarem em línguas diferentes, terem lançado números muito desiguais de discos e se lançarem originalmente em cenários díspares - o rock no caso de Rita, e o pop no caso das Spice Girls - as artistas também compartilham uma popularidade grande o suficiente para justificar a relevância de suas carreiras e, assim, sua inclusão no corpus de pesquisa. Tanto Rita Lee quanto as Spice Girls alcançaram sucesso notável não apenas em seus países de origem, mas também no exterior. Rita Lee é a 
mulher brasileira que mais vendeu discos no país (LEE, 2016, p.194), a artista com maior número de músicas em aberturas de novelas (LEE, 2016, p. 189), emplacou uma música em português na parada americana Billboard e teve seus discos lançados em países como México e Japão (LEE, 2016, p. 179). Por outro lado, as Spice Girls são o grupo feminino que mais vendeu discos em todos os tempos, tendo emplacado dez músicas de trabalho no top 10 das paradas do Reino Unido - a primeira delas, Wannabe, atingindo a primeira posição na lista das músicas mais vendidas e tocadas em 37 países (SINCLAIR, 2008).

Considerando que Rita Lee tem o extravagante número de 30 álbuns de estúdio lançados, e mesmo os exíguos três álbuns de estúdio das Spice Girls constituiriam um corpus considerável de 31 músicas, optamos por analisar apenas uma seleção de músicas das artistas e não suas discografias completas. A escolha das músicas a serem analisadas se deu através do Spotify, um dos mais populares serviços de streaming de música no mundo. Entre outras informações, o aplicativo do Spotify para computador apresenta, na página do intérprete, as músicas com maior número de execuções na plataforma. Optou-se por analisar as versões de estúdio em detrimento das versões ao vivo, muitas vezes caracterizadas por improvisos e intervenções da plateia. No caso de Rita Lee, também foi desconsiderada uma canção na qual a cantora é uma convidada, mas não a vocalista principal. Assim, o corpus final de músicas de Rita Lee consistia nas músicas Ovelha Negra, lançada em 1975, Mania de Você de 1979, Lança Perfume, de 1980, Amor e Sexo, de 2003, e Reza, de 2012. Já no caso das Spice Girls, não constavam entre as mais populares no Spotify versões ao vivo nem duetos, e as cinco músicas populares foram tomadas como corpus: Wannabe, 2 Become 1 e Say You'll Be There, lançadas em 1996, e Stop e Spice Up Your Life, de 1997.

Além das análises dos vocais nas músicas, conduzimos uma análise dos sotaques das artistas enquanto falavam. Como será demonstrado posteriormente, tal decisão se mostrou importante na interpretação dos dados e elaboração de conclusões. A análise do sotaque falado das artistas se deu através de gravações de vídeo. No caso de Rita Lee, julgou-se conveniente analisar duas amostras de épocas diferentes, haja vista a grande distância temporal entre as datas de lançamentos das músicas do corpus, que poderia implicar mudança na variedade linguística falada pela cantora ao longo do tempo. Registros de entrevistas de Rita Lee datados de antes dos anos 80 são bastante raros e, assim sendo, restou-nos utilizar um trecho de um especial televisivo da cantora Elis Regina em que Rita Lee aparece como convidada, interpretando duas canções e tendo uma rápida conversa com Elis. Também foi utilizado um trecho do DVD Biograffiti, lançado em 2007 (mais especificamente, os primeiros quatro minutos de Rita Fala, disponível nos extras do DVD). Registros audiovisuais de entrevistas das Spice Girls, por outro 
lado, são muito abundantes. Para esse trabalho, tomamos como referência os trechos gravados em estúdio do documentário Girls Talk! The Story so Far, disponível como bônus no DVD com o registro do primeiro show ao vivo do grupo. A fala de cada uma das cinco integrantes foi analisada separadamente.

As análises musicais foram, primeiramente, realizadas de oitiva, para identificação da variável fonética utilizada pelas cantoras consideradas. Esta análise preliminar é parte imprescindível do processo, uma vez que as músicas são distribuídas comercialmente (tanto no em plataformas de streaming quanto no formato físico Compact Disc, o CD) com os vocais mixados na mesma faixa dos instrumentos. Isto impede, em um primeiro momento, uma apreciação através de um software como o PRAAT (BOERSMA; VEENINK, 2021). Para viabilizar uma confirmação das análises, utilizamos outro software, o editor de áudio gratuito Audacity (AUDACITY TEAM, 2021), cujo próprio manual apresenta técnicas para isolar os vocais de uma música ${ }^{5}$. Este procedimento foi utilizado, principalmente, com as músicas de Rita Lee, particularmente com a canção Reza. Além disso, versões sem acompanhamento instrumental das canções do grupo Spice Girls estão disponíveis na plataforma de vídeos YouTube, algumas com os vocais isolados digitalmente por fãs, outras com as faixas vocais originais de estúdio (também chamadas de stems). As gravações de todas as fontes (CD físico, streaming e YouTube) foram comparadas, para garantir que não se tratava de takes vocais distintos. As análises de amostra de fala, por sua vez, não apresentavam ruídos ou instrumentos junto com as vozes, permitindo que a análise oitiva preliminar fosse seguida diretamente por confirmações de identificação no PRAAT.

\section{Análise I: Spice Girls (inglês britânico)}

Peter Trudgill (1983, p.251-252) aponta como regras e tendências da pronúncia usada por artistas britânicos em canções pop:

1. A pronúncia do /t/ intervocálico em palavras como better como um tepe alveolar vozeado [ $[$ ]

2. Ausência das pronúncias [a] e [a] em palavras como dance, half e can't

3. Pronúncia do /r/ em coda silábica

4. Monotongação dos ditongos em palavras como life e my

5. Modificação da vogal em palavras como love e done, pronunciadas como [ə]

6. Substituição da vogal [p] em palavras como body e top por [a]

\footnotetext{
${ }^{5}$ Disponível em: https://manual.audacityteam.org/man/tutorial_vocal_removal_and_isolation.html. Acesso em: 28 mai. 2021.
} 
Trudgill argumenta que, ainda que essas tendências estejam presentes em diversas variedades britânicas de inglês, nenhuma variedade falada no Reino Unido apresenta todas elas ao mesmo tempo. Assim, defende o autor, a adoção das pronúncias elencadas acima se configuraria em uma americanização do sotaque. Os aspectos analisados por Nunes e Azzi (2017) nas músicas do grupo The Beatles (roticidade e pronúncia do/t/) estão entre os elencados por Trudgill.

Outro dos aspectos apontados por Trudgill é o que o linguista Geoff Lindsey chama de “BATH-broadening” (LINDSEY, 2019, p. 42) e consiste na substituição da pronúncia histórica [æ] por [a] em palavras como dance, fast e bath. A pronúncia [a] para palavras desse grupo lexical não claramente definido ${ }^{6}$ é tratada não como uma variante, mas como uma regra e um elemento distintivo do dialeto britânico padrão em relação aos dialetos norte-americanos (SWAN, 1996 p. 44). Esse aspecto foi analisado por Konert-Panek (2017) na fala e na música da cantora londrina Adele.

Assim sendo, optamos por observar no corpus de músicas do grupo inglês Spice Girls se há 1-) vozeamento do fonema /t/ intervocálico no meio e no final de palavras, e consequente realização desse fonema como um tepe, 2-) BATH-broadening, 3-) pronúncia de /r/ em posição de coda silábica, fenômeno também chamado de BATH-TRAP split, pois ocasiona a diferenciação das vogais nas palavras bath e trap.

Ainda que todas as cinco integrantes do grupo Spice Girls sejam falantes nativas de inglês e tenham nascido na Inglaterra, suas origens - e, consequentemente, suas variedades linguísticas - não são homogêneas. Três das integrantes - Emma Bunton, nascida e criada no norte de Londres, Geri Halliwell, nascida e criada em Watford, e Victoria Beckham, nascida em Harlow e criada em Goffs Oak, ambas no sudeste da Inglaterra - são falantes de dialetos nitidamente oriundos do sul do país. Por outro lado, Melanie Brown, nascida e criada em um subúrbio de Leeds, e Melanie Chisholm, que cresceu em council estates de Widnes, próximo a Liverpool, apresentam sotaques do norte da Inglaterra. É importante notar que nenhuma delas é falante do padrão Received Pronunciation (RP), que se costuma tomar como referência para o inglês britânico. Na época em que as canções selecionadas para esse corpus foram gravadas, nenhuma das cantoras era fluente em outra língua além do inglês, e nenhuma delas tinha residido em qualquer outro país falante de inglês.

\footnotetext{
${ }^{6}$ Uma tendência observada é de que essa substituição ocorra antes de fricativas desvozeadas (por exemplo, em ask e after) e antes de uma nasal seguida por uma consoante (por exemplo, answer e demand). Porém, esta não é uma regra, já que palavras como plastic e trample fogem a essa tendência e são pronunciadas tipicamente com o som [æ] (LINDSEY, 2019, p. 42).
} 
Wannabe foi a primeira música de trabalho do grupo Spice Girls, e até hoje é sua canção mais popular. Os vocais não apresentam qualquer ocorrência de roticidade do fonema /r/ em posição de coda silábica, caracterizando uma evidência contra qualquer suposta americanização intencional da pronúncia das cantoras. Por outro lado, Melanie Chisholm e Emma realizam as vogais em past e fast como um [ع], distinto dos [a], [æ] e [a] esperados em dialetos britânicos. Ao mesmo tempo, todas as ocorrências em posição de meio de palavra, o fonema /t/ é realizado como um tepe $[\mathrm{r}]$ (em better e nas várias ocorrências da palavra gotta). O fonema /t/ também é realizado como tepe na maioria das vezes em que se encontra entre duas palavras seguido de um som vocálico do ponto de vista fonológico. As exceções, porém, são marcantes: ao final de cada refrão, as cinco vocalistas pronunciam a sequência it is como [I?IZ], com uma parada glotal que, nesse contexto, é bastante característica e reminiscente de dialetos britânicos. Outro desvio do padrão principal ocorre nas cinco repetições do verso "Slam your body down and wind it all around", no final da música, em que a sequência "it all" é pronunciada [I 'th $\mathrm{ll}]$, como um [t] marcado e claro, configurando a pronúncia estereotípica britânica.

Ouvidos mais atentos também perceberão a realização do fonema $/ \mathrm{r} /$ como uma aproximante labiodental [v], especialmente no começo da música, em what I really really want ${ }^{7}$. Essa realização de /r/ é rara nas variedades de inglês ao redor do mundo, e está mais associada a falantes do sul e do sudeste da Inglaterra, embora não esteja limitada a esses lugares e apareça até mesmo em centros urbanos da Escócia e do País de Gales (FOULKES; DOCHERTY, 2000).

Se Peter Trudgill (1983) estava certo ao ponderar que artistas britânicos adaptariam seu sotaque para se adequar ao gênero musical, Stop é a canção em que o grupo Spice Girls deveria exalar americanismos de forma mais notável. Stop é óbvia em suas influências Motown e blueeyed soul e na inspiração de grupos americanos como The Supremes. Ainda assim, é temerário dizer que ocorre, aqui, uma adoção de traços americanos em vez de uma redução de traços marcadamente britânicos.

Assim como em Wannabe, não há ocorrências do [a] estereotípico do sul da Inglaterra. De fato, nos três contextos em que essa vogal poderia aparecer (can't, fast e last) tem-se a pronúncia $[\varepsilon]$, mais elevada, em oposição às possibilidades mais típicas de variedades inglesas

\footnotetext{
${ }^{7}$ Outra explicação para a realização de /r/ como [v] seria a velocidade de elocução bastante rápida nesse trecho da composição. Como explicam Massini-Cagliari e Cagliari (2001, p.117), alterações na velocidade de fala, tanto para mais quanto para menos, tendem a acarretar problemas na articulação, sendo que quanto maior a mudança, maior a tendência de perda de clareza e inteligibilidade da fala. Porém, este não é o caso aqui. A sequência "really really want" é pronunciada em seguida por Melanie Brown e Geri Halliwell, na mesma velocidade, e é possível perceber que Brown realiza o fonema como uma aproximante, [৩], mas Halliwell, não. Se ambas cantam o trecho de forma igualmente rápida, isso mostra que a velocidade de fala não é o fator que determina a ocorrência de [0] - ou, pelo menos, não é o único fator, nem o mais importante.
} 
([a], [æ] e [a]). No mesmo sentido, todos os /t/ em posição intervocabular seguidos de sons vocálicos são realizados como tepe. O mesmo ocorre com /t/ em posição de meio de palavra, aqui representado pelas várias instâncias da palavra gotta, também pronunciada com tepes. Isso poderia sugerir uma americanização da pronúncia.

No entanto, os vocais são consistentemente não róticos, o que seria incoerente com uma americanização do sotaque, já que a ideia que se tem de um dialeto americano inclui forte roticidade - ainda que, na realidade, tal característica não se aplique a todos os dialetos (TRUDGILL, 1983, p. 256). O resultado sonoro é, assim, ambíguo.

Em 2 Become 1 não há ocorrências de /r/ em posição de coda - a pronúncia das cantoras na canção é consistentemente não rótica. Também não se encontram ocorrências de substituição de [a:] por [æ], pois a letra não apresenta qualquer palavra do grupo lexical em que essa troca possa ocorrer. Mais interessante, aqui, é a variação na realização do fonema /t/.

$\mathrm{Na}$ maior parte das vezes, o fonema /t/ é pronunciado como um tepe $[\mathrm{f}]$ no meio de palavras (como em "come a little bit closer") e no final de palavras seguido de um som vocálico do ponto de vista fonológico (como em “take it or leave it”). Entretanto, é notável a presença da realização de /t/ como pausas glotais, [?] nas duas vezes em que Melanie Chisholm canta "let's work it out boy". A realização [?] também aparece na voz de Emma, em um contexto ainda mais interessante: em um verso em que as palavras são repetidas ("put it on, put it on"), a pronúncia de Emma é a de um tepe [r] nas duas vezes em que pronuncia a palavra put, mas [?] na primeira vez em que pronuncia it, voltando ao tepe no final. Efetivamente, ouvimos [porıPon] seguido de [porıron]. As possíveis implicações dessa alternância serão discutidas mais adiante.

Em Spice Up Your Life, a única ocorrência de um /r/ em coda silábica se dá em um trecho de fala ritmada aproximadamente aos 1'59' : Melanie Brown pronuncia a última vogal na frase "But hip-hop is harder" e, em seguida, articula um quase imperceptível /r/ retroflexo na coda silábica de harder. Fora essa única (e quase irrelevante) exceção, todos os vocais são consistentemente não-róticos, sem realizações de /r/ em coda silábica. Mais uma vez, as cantoras evitam o uso de [a:] em dancing, adotando a pronúncia [æ].

Aponte-se, entretanto, leves inconsistências entre as cantoras. A vogal de having (em "If you're having a good time") é pronunciada como um [a] por Victoria, mas como [æ] por Melanie Chisholm. Em outro momento, Emma e Melanie Brown pronunciam o segundo /t/ da palavra positivity como um [t], enquanto Geri realiza o fonema como um tepe [r]. Ainda assim, quando os vocais são sobrepostos, tem-se a nítida impressão de um [t] uníssono. Desta forma, chama atenção a pronúncia bastante marcada de [t] não só na palavra positivity, mas também 
em fighting (“Kung Fu Fighting, Dancing Queen”), ambas em posição de final de verso e, consequentemente, destacadas na linha melódica. Ao contrário do que se esperaria no caso de uma emulação de sotaque americano, a pronúncia de /t/ é a de um [t] estereotipicamente inglês, em vez do tepe $[\mathrm{r}]$ esperado de um americano. É possível que o [t] plosivo em fighting seja um aceno à pronúncia na canção a qual esse verso faz referência, Kung Fu Fighting, do cantor jamaicano Carl Douglas, e que a pronúncia de positivity na música tenha sido padronizada em razão de fighting. Ainda assim, caso as cantoras estivessem tentando emular um sotaque americano, a realização de um tepe em positivity e em fighting ainda seria suficientemente clara e aceitável, não prejudicando a referência musical. Assim, seja ou não um aceno à pronúncia original na canção a que fazem referência, o fato é que o resultado final é uma pronúncia tipicamente associada ao inglês britânico, marcadamente distinta da esperada de um dialeto americano.

Em Say You'll Be There, as Spice Girls apresentam uma pronúncia predominantemente não rótica, exceto por dois momentos: em "we're going round in circles", Emma articula um brevíssimo /r/ ao final de we're, antes de voltar para a não-roticidade em circles, e em "there is no need", Victoria articula claramente um /r/ entre there e is (em um contexto em que, mesmo em dialetos não róticos, a presença de um /r/ é possível). Essas duas ocorrências à parte, nenhum /r/ em posição de coda é pronunciado. $\mathrm{O}$ fonema /t/ no meio de palavras é realizado como tepe [r] em suas quatro ocorrências (três vezes na palavra gotta, uma vez em better). Nesse sentido, vale também apontar a ocorrência de tepe todas as vezes em que o fonema /t/ aparece no final de palavras seguido por um som vocálico do ponto de vista fonológico (como em “... that I..."). Por fim, aqui as cantoras também evitam a pronúncia [a:] em favor de [æ] (em last e can't).

Nas amostras de fala, as cinco integrantes do grupo apresentam pronúncias consistentemente não-róticas, o que também é consistente com as pronúncias apresentadas nas músicas. Em relação à pronúncia das palavras do grupo lexical bath com o som [a:], corpus falado analisado apresentou quantidades muito diferentes de ocorrências na fala das Spice Girls, mas parece claro que a clássica diferença entre dialetos do sul da Inglaterra, apresentando a divisão BATH-TRAP, e o norte, mantendo apenas a vogal [a] (também chamada de flat a), está presente entre elas. Em que pese a escassez de ocorrências, tanto a pronúncia de Melanie Brown, na ocorrência da palavra dance, quanto a de Melanie Chisholm, na palavra dancer, apresentam um [a] baixo, o que é esperado, já que ambas são do norte do país. Emma Bunton claramente apresenta a divisão BATH-TRAP, com múltiplas ocorrências do grupo lexical de $B A T H$ sendo pronunciado como [a]. Geri Halliwell também parece apresentar a divisão, porém de forma menos estatisticamente pronunciada do que Emma, devido ao menor número de 
ocorrências. A fala de Victoria não apresentou ocorrências que permitissem verificar a ocorrência da divisão.

Outro aspecto interessante é a pronúncia de /t/: todas as integrantes, em maior ou menor grau, apresentaram a realização desse fonema como uma oclusiva glotal [?], tanto em contexto intervocálico no meio de palavras (como em little, getting e security) quanto no contexto de limite de palavras (por exemplo, em a lot of, get out e got a). Esta realização foi, de longe, a mais comum do fonema/t/. Victoria, Geri, Melanie Chilsholm e Melanie Brown também apresentaram a realização [t] em contexto intervocálico no meio de palavras (como em letter e gutted), embora Melanie Brown só tenha apresentado essa realização em uma ocorrência (em nightie). Emma Bunton não apresentou a realização [t] nesses contextos, mas sim [?]. A realização de /t/ como um tepe [r] em posição intervocálica entre palavras também foi bastante comum, ocorrendo na fala de quatro das cinco integrantes, Geri Halliwell sendo a exceção. Por fim, a realização de /t/ como um [t] esterotipicamente britânico em posição intervocálica entre palavras foi verificada apenas na fala de Geri e Victoria, e ainda assim de forma apenas esporádica (como em at a e caught up). As figuras 2 e 3 mostram a variação na realização do fonema /t/ na fala de Victoria Beckham, com poucos segundos separando as pronúncias distintas.

Os dados levantados até agora já mostram a importância de se atentar ao padrão do dialeto em relação ao qual se quer analisar as mudanças na pronúncia. Ao analisar a evolução dos sotaques nas canções do grupo The Beatles, Nunes e Azzi (2017) elegem as pronúncias de /t/ e de /r/ como foco e adotam como pontos de referência as variedades General American, para o inglês americano, e Received Pronunciation, para o inglês britânico. Tal escolha é bastante problemática, uma vez que nenhum dos quatro integrantes da banda era falante de RP, que apresenta diferenças significativas do dialeto típico da região de Liverpool. Não apenas isso, a própria noção de RP como dialeto britânico padrão é questionável: ainda que o padrão Received Pronunciation seja praticamente onipresente em livros didáticos de língua inglesa, a percepção atual sobre o RP entre falantes nativos é de que se trata de um dialeto já fora de moda, até mesmo cômico (LINDSEY, 2019). A descrição dos dados de fala das Spice Girls mostra de forma clara quão problemática é a decisão de Nunes e Azzi, já que mesmo as três integrantes do sul da Inglaterra desviam do padrão RP e apresentam inconsistências entre si. A adoção automática do RP como parâmetro para investigar a acomodação fonológica de intérpretes britânicos já se mostra inadequada se aplicada a falantes do sul, pior se aplicada a falantes do norte, como os Beatles ou as duas Melanies. 
Figura 2 - Pronúncia do fonema /t/ como oclusiva desvozeada na fala de Victoria Beckham, na sequência "lot up"

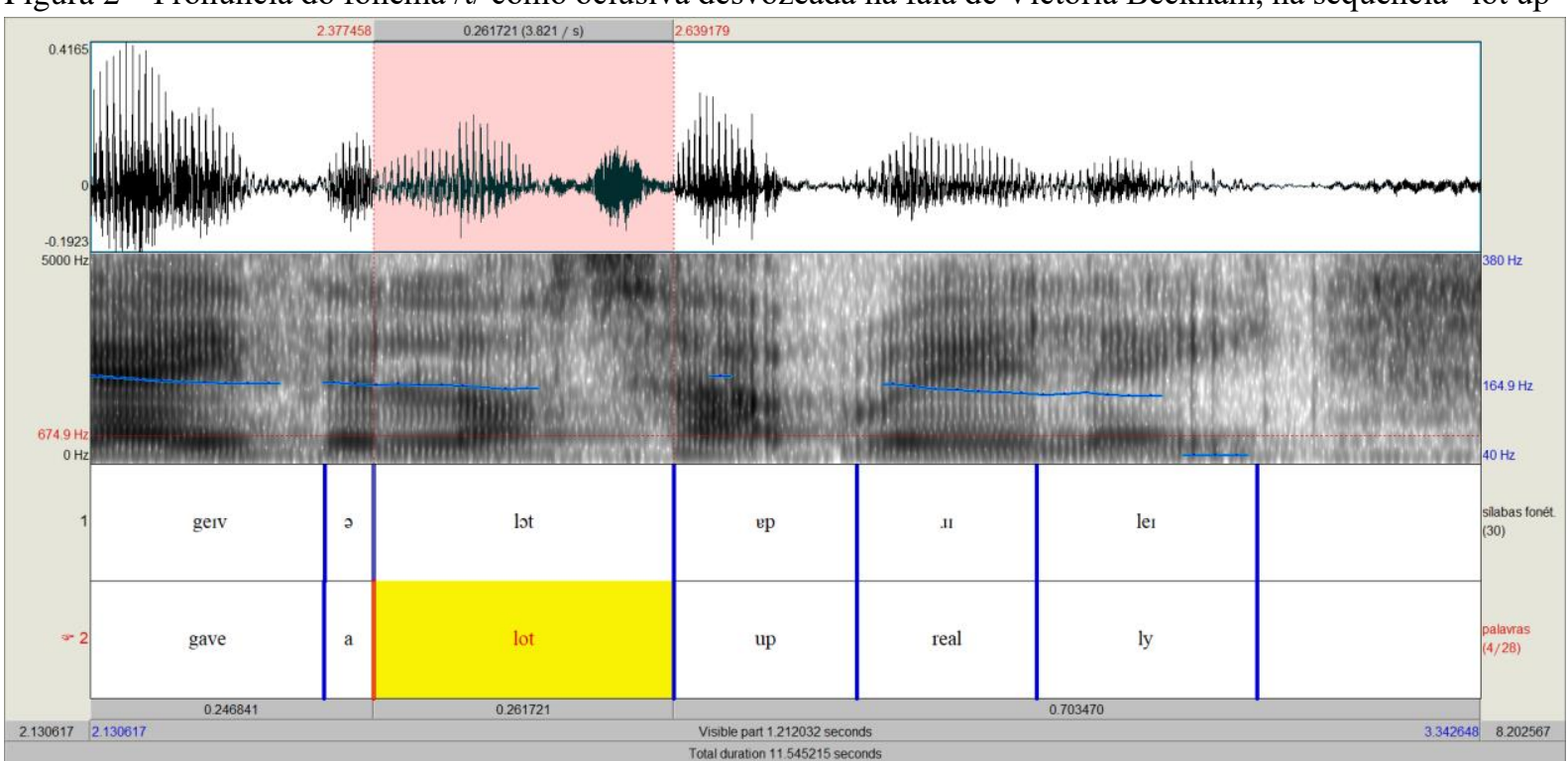

Fonte: elaboração própria.

Figura 3 - Pronúncia do fonema /t/ como tepe vozeado na fala de Victoria Beckham, na sequência "What I'm"

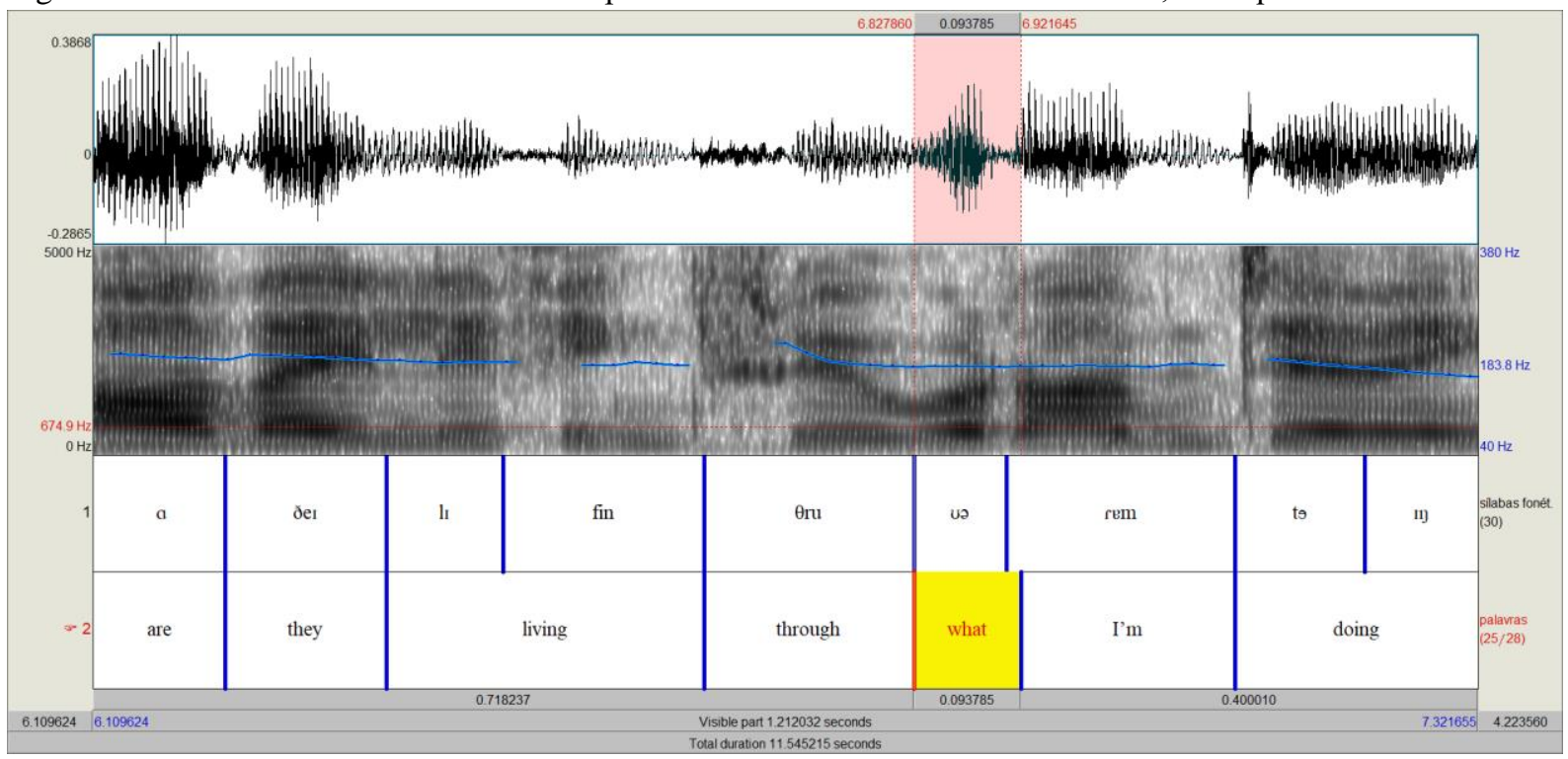

Fonte: elaboração própria.

Geoff Lindsey (2019), em sua revisão da descrição fonológica padrão de variedades do inglês do sul do Reino Unido, defende que, apesar de na maior parte do século XX o fenômeno de BATH-broadening ter sido considerado desejável e até mesmo necessário, mudanças sociais na sociedade britânica fizeram com que a vogal [æ] se configurasse como uma alternativa totalmente aceitável no inglês britânico padrão do Sul:

These differences still exist, but social changes have taken place in Britain. Throughout most of the twentieth century, RP occupied such a special position of privilege and prestige that deviations from it were looked down on in many walks of life. Official BBC announcers and newsreaders, for example, were expected to be strict RP speakers, with BATH-broadening. 
Today greater diversity is allowed, even among BBC newsreaders, documentary narrators, etc. It's now common for such speakers to have un-broadened TRAP in bath, after, ask, answer, demand, chant, sample, etc. We might say that SSB now includes un-broadened BATH words as an option. (LINDSEY, 2019, p. 42)

Lindsey também nota que milhões de falantes do norte da Inglaterra não apresentam a distinção entre as vogais de bath e trap, e esse parece ser o caso de Melanie Chilsholm e Melanie Brown. Também vale mencionar, aqui, a atitude negativa, por vezes até hostil, de muitos falantes do norte em relação à pronúncia [a] (GUPTA, 2005, p. 25). Essas ponderações, se comparadas à análise de Konert-Panek (2017) das pronúncias apresentadas na fala e no canto da cantora londrina Adele, parecem deixar claro que existem outros fatores além da dualidade britânico x americano na pronúncia da música popular. No caso de Adele, a cantora apresenta a distinção BATH-TRAP de forma marcada e constante na fala e no primeiro disco, mas essa mesma distinção é suprimida no seu segundo - e mais bem-sucedido internacionalmente álbum. Já no caso das Spice Girls, o corpus aqui indica a ausência dessa divisão é constante nas músicas dos dois discos, e há de se considerar que parte considerável do grupo sequer apresenta essa divisão na fala. Obviamente, ainda há que se explicar o porquê de a vogal em can't ter sido levantada nas músicas Wannabe e Stop. Nesse caso, pode-se especular que, de fato, houve uma tentativa de soar mais "internacional” - note-se que não falamos de "soar mais americano", já que em nenhum momento as cantoras adotam uma pronúncia rótica. O levantamento das vogais em past e last, por exemplo, também pode ter a mesma motivação. De todo modo, atribuir a ausência da realização [a] a uma americanização da pronúncia é instintivo e tentador, mas também temerário, pelo menos no caso das Spice Girls: ao invés disso, sugerimos aqui que houve um movimento de normalização entre as pronúncias de todas as integrantes, e uma tentativa de redução das características mais marcadas de sotaques regionais, o que não se confunde com a adoção de um padrão fonológico de outro dialeto.

Já no que se refere à pronúncia de /t/, parece-nos evidente que as realizações de /t/ como um tepe não correspondem a um afastamento da identidade linguística britânica das integrantes do grupo. Especulamos que a quase padronização do /t/ como um tepe se deva a dois fatores: 1-) esse alofone está presente na fala da maioria das integrantes, 2-) a pronúncia [?], bem como [t], implica uma breve suspensão da vibração das cordas vocais, o que poderia gerar um efeito de quebra na linha melódica. De todo modo, considerando o contexto, parece pouquíssimo provável que essa padronização tenha se dado na intenção de americanizar as pronúncias. 


\section{Análise II: Rita Lee (português brasileiro)}

De acordo com sua autobiografia (LEE, 2016), Rita Lee nasceu em e cresceu na Vila Mariana, em São Paulo. Sua mãe era filha de imigrantes italianos, e seu pai era filho de norteamericanos. Apesar das origens estrangeiras de seus pais, Rita é falante nativa de português, ainda que fluente em inglês. Estudou no colégio franco-brasileiro Liceu Pasteur. Em 1976, conheceu o carioca Roberto de Carvalho, com quem viria a estabelecer uma parceria musical e amorosa que dura até os dias atuais. Apesar de ter viajado extensivamente ao longo de mais de cinquenta anos de carreira, Rita Lee sempre manteve residência fixa no estado de São Paulo.

Nas canções de Rita Lee, procuramos ocorrências que destoem do dialeto paulista/paulistano típico. Um dos fonemas que apresenta maior variação entre dialetos do Português Brasileiro é o $/ \mathrm{R} /{ }^{8}$ em posição de travamento silábico, especialmente em posição pósvocálica, em coda silábica. Sendo uma falante que adquiriu a língua materna e viveu a vida toda na região de São Paulo capital, é esperado que Rita Lee realize o /R/ nesse contexto como uma vibrante simples, ou tepe, pronúncia típica dessa região (MONARETTO; QUEDNAU; DA HORA, 2001, p. 205). Também é esperada a realização consistente do /s/ pós-vocálico como uma consoante alveolar, e não uma palatal, como tipicamente ocorre no Rio de Janeiro e no Recife (MONARETTO; QUEDNAU; DA HORA, 2001, p. 204).

Ovelha Negra é um dos primeiros sucessos da carreira solo de Rita Lee. O disco Fruto Proibido, do qual a canção faz parte, é considerado um dos discos seminais do rock brasileiro. Obviamente, não se pode dizer que não se produzia rock no Brasil antes de Fruto Proibido, mas o fato é que o disco, com sua instrumentação mais pesada e notáveis influências de hard rock misturadas ao pop, é mais um precursor do que um seguidor da tradição de rock em língua portuguesa no Brasil. Essas observações são importantes, pois se (como defende Peter Trudgill) um dos fatores que desencadeia a adaptação fonológica em intérpretes é a acomodação a um

\footnotetext{
${ }^{8} \mathrm{O}$ uso da letra maiúscula entre barras inclinadas para representar uma consoante rótica indica a consideração de que, nesse contexto linguístico, ou seja, na posição de travamento silábico, os autores deste artigo assumem a grande variação com que a rótica pode ser realizada em nível fonético. Em outras palavras, assumem a noção de arquifonema adotada por Camara Jr. (1970[1985]), em obra póstuma não revisada em vida pelo autor, ainda que ele, especificamente para a rótica, considere a ocorrência dos fonemas $/ \mathrm{r} / \mathrm{e} / \mathrm{r} / \mathrm{em}$ todas as suas variantes fonéticas nesse contexto. Silva (2001, p. 161) afirma que “o «R» posvocálico é representado pelo arquifonema /R/”. MassiniCagliari, Cagliari e Redenbarger (2016, p. 59-60) sumarizam toda a polêmica envolvendo a consideração de um ou mais fonemas róticos em Português Brasileiro e Português Europeu, seu status em posição de travamento silábico, além de discutirem a possibilidade de geminação das róticas em posição intervocálica. Cagliari (2007, p. 44) mostra que "o que se escreve com R ou RR, seguindo o sistema ortográfico do Brasil, pode ter muitas pronúncias diferentes, dependendo do contexto lingüístico e do dialeto. Assim, o que se escreve com RR pode ter como pronúncia $[\rho,\{, \xi, \otimes, \Xi, \circledR, \eta, \mid]$, e o que se escreve com $\mathrm{R}$ pode ter como pronúncia $[\mathrm{r}, \mathrm{r} 8,\{, \mathrm{P}, \mathrm{P} 8, \mathrm{P}, 8 \triangleleft 8$, $\bullet f,(\subset, \xi, \otimes, \Xi, \circledR, \eta, \mid]$ ”. As referências arroladas nesta nota mostram, pois, as dificuldades em considerar uma pronúncia específica de consoante rótica, ou, em outros termos, "aquilo que se escreve com r", como típica ou atípica de variedades do português falado no Brasil.
} 
gênero musical, essas forças seriam, no mínimo, menos fortes nessa fase da carreira de Rita Lee, uma vez que a força da tradição a levaria, provavelmente, a compor e cantar em inglês, e não a adotar um dialeto específico do Português Brasileiro.

Do ponto de vista fonético-fonológico, a pronúncia apresentada em Ovelha Negra destoa das expectativas para um falante paulistano (ainda que não fuja ao padrão estabelecido pela cantora, como veremos a seguir). A pronúncia do arquifonema /R/ como um tepe $[r]$ na posição de travamento silábico só aparece em um verso, repetido duas vezes, no qual o arquifonema /R/ é seguido por uma vogal sem pausa na fonação ("não vale a pena esperar, oh não"). Em todas as outras ocorrências, o fonema ou não é realizado ("sem saber") ou é realizado como uma fricativa, aqui transcrita como [h]. No mais, não encontramos em Ovelha Negra outras ocorrências fonéticas que poderiam indicar acomodação fonético-fonológica a um dialeto diferente.

Mania de Você e Lança Perfume apresentam padrões de pronúncia idênticos. A música Lança Perfume apresenta 39 ocorrências de /R/ em posição de travamento silábico. Destas 39 ocorrências, a maioria esmagadora (37) é realizada como uma fricativa [h], com apenas duas ocorrências de tepe: nas duas repetições de "não dá pra ficar imune", em que a ressilabação transforma o /R/ no final de ficar em ataque da primeira sílaba de imune. Essa ressilabação que ocorre em ficar imune, no entanto, não provoca a ocorrência de tepe no final do pré-refrão, em que "de amor, ô" é realizado como [amoh.o]. Tem-se, assim, que o fone [h] aparece antes de pausas na fonação e de consoantes, com uma ocorrência marginal precedendo uma vogal [i]. O mesmo pode ser observado em Mania de Você, em que os tepes se encontram restritos ao contexto de ressilabação, nas quatro repetições do verso "só pra deitar e rolar com você" (quatro ocorrências de tepe contra 35 de fricativa).

Ao contrário da relativa consistência encontrada nas músicas anteriores, a realização do fonema /R/ é muito mais variada na música Amor e Sexo. Das 28 ocorrências do fonema, temos 11 realizações como fricativa e 17 realizações como tepe, além de um apagamento ("Amor [amo] vem de nós...") e até mesmo a ocorrência de uma vibrante múltipla ("nos torna [torna] patéticos"). É interessante notar que, exceto quando há uma pausa na fonação entre a consoante e a vogal, todas as ocorrências de /R/ seguido por uma vogal desencadeiam a ocorrência de tepe e de ressilabação. Por outro lado, é relativamente surpreendente, em vista do exposto em outras músicas até agora, a ocorrência de um tepe ("sexo é esporte [isporţi]”) e, principalmente, de uma vibrante antes de [n], sendo que no mesmo contexto, na palavra carnaval, há a realização de /R/ como [h]. Por fim, é curiosa a presença de nasalização do primeiro <a > na palavra animal, em um contexto em que tal nasalização não seria esperada em um dialeto paulista. 
A letra de Reza não apresenta contextos que desencadeiem a ressilabação de /R/ em posição de coda silábica, nem /R/ antes de pausa. As poucas ocorrências do arquifonema aparecem antes de consoante, e em todas elas a realização que se observa é a de uma fricativa $[\mathrm{h}]$.

Depois das canções, analisamos as amostras de fala espontânea. Apesar da duração bastante breve da primeira amostra, é possível perceber que, em 1978, a pronúncia de Rita Lee destoa do esperado para uma falante paulistana. Das três ocorrências de /r/ pós-vocálico, duas são realizadas como fricativas ("super sozinho", "uma cartinha sua") e uma como zero fonético (“nascer quadrado") $)^{9}$. Mais curiosa é a realização do /s/ pós-vocálico como uma consoante palatal desvozeada [S] (“aquelas coisa").

A amostra de fala de 2007, mais longa, permite traçar um retrato mais preciso e detalhado da pronúncia de Rita Lee. Ao longo de sua fala, a cantora apresenta pronúncia de /r/ em posição de coda predominantemente como um tepe [r] (como em "Bárbara", "virgem" e "mártir"), mas é notável a ocorrência também frequente da consoante fricativa [h] (como em "sair" e "perfeito"). Ocasionalmente, Rita emprega uma vibrante múltipla [r] ("o andor, né"), o zero fonético (“comecei a gostar do fumacê aí!"), esperado na fala paulistana, e uma fricativa uvular $[\chi]$ bastante pronunciada, esta última pronúncia provavelmente de forma deliberada e com fins estilísticos (“Mas nem morta!"). A figura 4 mostra realizações distintas de /R/ na fala de Rita Lee, com poucos segundos separando as duas pronúncias distintas. Também vale a pena notar que, apesar de Rita ser consistente na pronúncia de /s/ em coda como uma consoante alveolar [s], a certa altura ela emprega a pronúncia palatal [ $\left.\int\right]$ na palavra "meninas", também provavelmente de forma deliberada e estilística. Por último, note-se que, no que poderia ser um lapso, a cantora pronuncia a sílaba "gos" com uma fricativa palatal desvozeada [S] na coda, no que parece ser uma enunciação interrompida do morfema gost- ("o incenso, cheiro de incenso, hum... gos... comecei a gostar do fumacê aí!”). É possível especular se, em algum nível, Rita tem internalizada a fricativa palatal como uma possível realização do fonema /s/.

\footnotetext{
9 Não nos aprofundamos, aqui, no apagamento do -r final de infinitivo verbal, pois essa pronúncia é tão disseminada pelo Português Brasileiro a ponto de não se configurar como um marcador fonológico de dialetos específicos.
} 
Figura 4 - Variação na pronúncia de /R/ na fala de Rita Lee: tepe e fricativa uvular surda

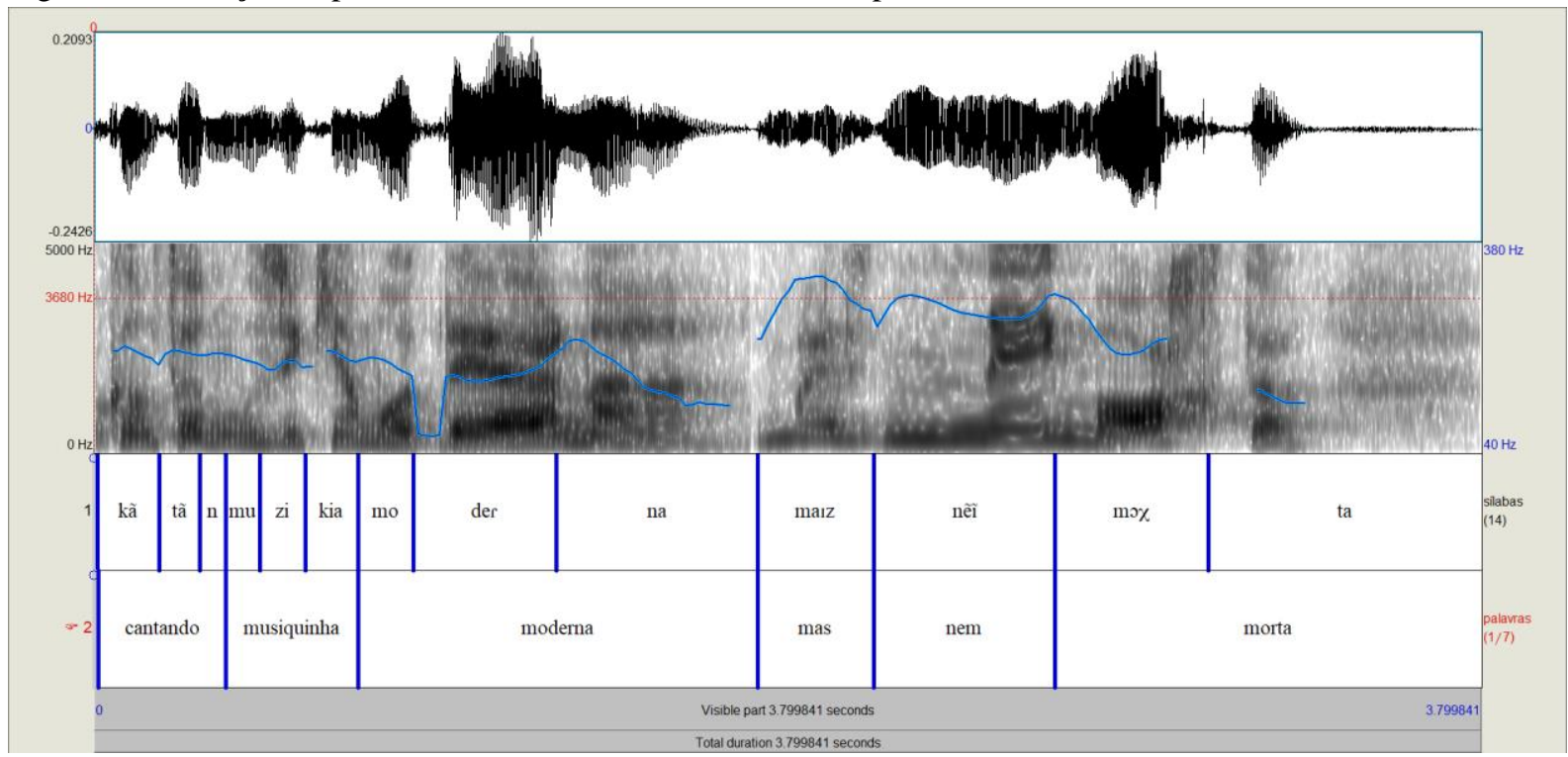

Fonte: elaboração própria.

Os estereótipos e as expectativas são claros: /r/ em coda silábica tem pronúncia alveolar para os paulistanos, fricativa para os cariocas. Ao analisar a pronúncia de Rita Lee em suas músicas, seria possível pensar que o emprego da consoante fricativa corresponde a um uso estilístico deliberado ou, na linha da argumentação de Peter Trudgill, à adoção possivelmente inconsciente de um padrão fonológico de outras variedades associadas aos gêneros musicais pelos quais Rita transita. O histórico da cantora, que antes de se lançar em carreira solo participou do movimento da Tropicália ao lado de nomes como os baianos Caetano Veloso e Gilberto Gil, e que ao longo da carreira incorporou fortes influências de bossa nova e MPB em suas composições, poderia dar força a essa interpretação. Afinal, se lembrarmos da grande influência de compositores e intérpretes cariocas como Tom Jobim e João Gilberto na Bossa e na MPB, e se tivermos em mente que foi com Caetano Veloso e Gilberto Gil que Rita "se abriu" à possibilidade de compor em português (LEE, 2016, p. 75), não seria estranho pensar que a cantora poderia ter adotado características das variedades baianas e carioca em seu canto, talvez por associá-las mais à noção de brasilidade.

Essas conclusões, no entanto, tornam-se menos óbvias quando se tem em mente que Rita Lee apresenta uma fala consideravelmente inconsistente no que se refere à realização do /r/ pós-vocálico. O uso das fricativas em suas músicas, apesar de "pouco paulistano", não é um desvio tão radical da pronúncia utilizada por Rita normalmente. A presença dos tepes tipicamente paulistanos e a constante "associação voluntária" por parte da cantora à cidade de São Paulo (basta lembrar, por exemplo, que um de seus álbuns de estúdio se chama justamente Santa Rita de Sampa) não indicam qualquer tentativa de Rita Lee de se desvencilhar da 
identidade paulistana, ainda que sua identidade fonológica possa soar incongruente para alguns ouvintes.

Pode-se especular, também, que o sotaque de Rita teria assimilado traços distintos devido à convivência com seu marido carioca, Roberto de Carvalho. No entanto, a análise da fala de Lee em 1978 enfraquece essa teoria, já que na época a cantora já apresentava uma pronúncia "pouco ortodoxa" e, naquela ocasião, seu relacionamento com Roberto de Carvalho ainda era recente.

Qualquer explicação que se dê para as pronúncias observadas nos vocais de Rita Lee deve levar em conta que não há uma alteração ou suavização de sotaque em suas músicas, mas uma padronização, uma escolha por um dos alofones que a cantora utiliza naturalmente em sua fala. Da análise das canções de Rita, fica a lição de que é importante conjecturar sobre adaptações estilísticas a partir da pronúncia apresentada pelo falante/intérprete em questão, e não de uma generalização acerca de uma variedade linguística que assumimos - erroneamente ou não - ser a desse falante.

\section{Considerações finais}

A língua é dinâmica, e é preciso ter isso em mente quando amparamos nossas análises em descrições anteriores. Não apenas isso, é preciso se certificar que a descrição adotada como referência é adequada ao corpus de análise. Neste artigo, buscamos mostrar a importância de atentar para esse aspecto.

Rita Lee, apesar de paulistana, apresenta uma pronúncia dos fonemas /R/ que, ocasionalmente, desvia do estereótipo paulistano. Evidentemente, pode-se especular acerca das razões desse desvio. Porém, se tomarmos suas canções como corpus de análise para verificar as forças atuantes sobre as constrições na pronúncia da música popular brasileiro possivelmente, também um embate constante que coloca a identidade contra a acomodação às expectativas do gênero musical e da plateia - devemos partir de uma comparação com sua própria fala espontânea, e não de apenas uma descrição geral do dialeto de sua região e classe social.

O mesmo também pode ser observado através da análise da pronúncia das inglesas Spice Girls, em que a adoção do RP, o modelo tradicional de "inglês britânico", distorceria completamente as conclusões - levando-nos a acreditar, por exemplo, que qualquer pronúncia de /t/ que não [t] seria um desvio, o que vimos não ser verdade.

Por fim, ponderamos que a percepção geral de que "artistas britânicos perdem o sotaque ou soam como americanos" ao cantar é apenas uma meia-verdade. Enquanto alguns aspectos 
do sotaque, como a prosódia, de fato se perdem, e apesar de termos observado, nesse corpus, alterações na qualidade das vogais, os indícios da identidade fonológica britânica continuam presentes na não-roticidade e na ocasional ocorrência de uma oclusiva glotal, [?]. Se alguém tiver a impressão de que as Spice Girls não soam inglesas, talvez este ouvinte não esteja ouvindo com tanta atenção, ou tenha uma representação engessada do que significa "soar inglês". Ou, quem sabe, as duas coisas.

\section{Referências}

ADAMS, C. Why do English singers seem to lose their accent when they sing? Connect Savannah. 10 de maio de 2017. Disponível em:

https://www.connectsavannah.com/savannah/why-do-english-singers-seem-to-lose-theiraccent-when-they-sing/Content?oid=4728305. Acesso em: 22 mar. 2021.

AUDACITY TEAM. Audacity (R): Free Audio Editor and Recorder. Versão 3.0.0, 2021. Disponível em: https://www.audacityteam.org/. Acesso em: 17 mar. 2021.

ASSIS, A. B. G. Adaptações fonológicas na pronúncia de estrangeirismos do Inglês por falantes de Português Brasileiro. 2007. Dissertação (Mestrado em Linguística e Língua Portuguesa) - Faculdade de Ciências e Letras, UNESP, Araraquara, 2007.

BOERSMA, P.; WEENINK, D. Praat: Doing Phonetics by Computer [Computer program]. (Version 6.1.39), 2021. Disponível em http://www.praat.org/. Acesso em: 27 mar. 2021.

CAGLiARI, L. C. Elementos de Fonética do Português Brasileiro. São Paulo: Paulistana, 2007.

CAMARA JR., J. M. Estrutura da Língua Portuguesa. 15. ed. Petrópolis: Editora Vozes Ltda., 1985. [1ª edição: 1970].

COSTA, D. S. A interface música e lingüística como instrumental metodológico para o estudo da prosódia do português arcaico. 2010. Tese (Doutorado em Linguística e Língua Portuguesa) - Faculdade de Ciências e Letras, UNESP, Araraquara, 2010.

CRYSTAL, D. On singing accents. DCBlog. 2009. Disponível em: http://davidcrystal.blogspot.com.br/2009/11/on-singing-accents.html. Acesso em: 26 mar. 2021.

FOULKES, P.; DOCHERTY, G. J. Another chapter in the story of /r/: "Labiodental" variants in British English. Journal of Sociolinguistics, v. 1, n. 4, p. 30-59, 2000. Doi: 10.1111/14679481.00102

GIRLS Talk! The Story so Far. In: Spice Girls: Girl Power! Live in Istanbul. 1 DVD (25m19s), 2007. Extras do DVD.

HONEYCUTT, D. Why British Singers Lose Their Accents When Singing. Today I Found Out. 09 de agosto de 2013. Disponível em: 
http://www.todayifoundout.com/index.php/2013/08/why-british-singers-lose-their-accentwhen-singing/. Acesso em: 25 mar. 2021.

KONERT-PANEK, M. Overshooting Americanisation. Accent stylisation in pop singingacoustic properties of the bath and trap vowels in focus. Research in Language, v. 4, n. 15, p. 371-384, 2017. Disponível em: https://doi.org/10.1515/rela-2017-0021. Acesso em: 14 jul. 2021.

LEE, R. Rita Lee: uma autobiografia. São Paulo: Globo, 2016.

GUPTA, A. F. Baths and becks: A report on two prominent dialectal variables in England. English Today 81, v. 21, n. 1, p. 21-26, 2005.

LEE, R. Rita Fala. In: Biograffiti. 3 DVDs, (15m06s), 2007. Extras do DVD 1.

LEE, R. Rita Lee: uma autobiografia. 1. ed. São Paulo: Globo, 2016.

LINDSEY, G. English After RP: Standard British Pronunciation Today. Palgrave Macmillan, 2019. E-book.

MASSINI-CAGLIARI, G. Das cadências musicais para o ritmo linguístico: uma análise do ritmo do Português Arcaico, a partir da notação musical das Cantigas de Santa Maria.

Revista da ABRALIN, v. 7, n. 1, p. 9-26, 2008.

MASSINI-CAGLIARI, G. From Musical Cadences to Linguistic Prosody: How to Abstract Speech Rhythm of the Past. In: PARTRIDGE, J. (Ed.). Interfaces in language. Newcastle upon Tyne: Cambridge Scholars, 2010. p. 113-134.

MASSINI-CAGLIARI, G. Contribuição para a análise do ritmo linguístico das cantigas medievais profanas e religiosas a partir de uma interface Música-Linguística. In: REBELO, H. (Coord.) Lusofonia: Tempo de Reciprocidades. Actas do IX Congresso da Associação Internacional de Lusitanistas. Madeira, 4 a 9 de agosto de 2008. Porto: Edições Afrontamento, 2011a. Vol. I. p. 41-53.

MASSINI-CAGLIARI, G. Adaptação fonológica de nomes próprios de origem estrangeira: comparação entre Português Arcaico e Português Brasileiro. Estudos Linguísticos, São Paulo, v. 40, n. 2, p. 795-807, 2011 b.

MASSINI-CAGLIARI, G.; CAGLIARI, L. C. Fonética. In: MUSSALIM, F.; BENTES, A. C. (Orgs.). Introdução à lingüística: domínios e fronteiras. São Paulo: Editora Cortez. 2001. p. 105-146.

MASSINI-CAGLIARI, G.; CAGLIARI, L. C.; REDENBARGER, W. J. A Comparative Study of the Sounds of European and Brazilian Portuguese: Phonemes and Allophones. In: WETZELS, W. L.; MENUZZI, S.; COSTA, J. (Eds.) The Handbook of Portuguese Linguistics. Oxford: Wiley-Blackwell, 2016. p. 56-68.

MONARETTO, V. N. O.; QUEDNAU, L. R.; DA HORA, D. As Consoantes do Português. In: BISOL, L. (Org). Introdução a estudos de fonologia do português brasileiro. 3. ed. Porto Alegre: Edipucrs, 2001. p. 207-241. 
NUNES, M. B.; AZZI, J. N. Did America Invade The Beatles as they invaded America? - A comparative analysis on The Beatles' accent in former and later years. Entrepalavras, v. 7, n. 4, p. 46-65, 2017. Disponível em:

http://www.entrepalavras.ufc.br/revista/index.php/Revista/article/view/639. Acesso em: 25 mar. 2021.

Rita Lee e Elis Regina - Completo - 1978. 2013. (7m20s). Disponível em: https://youtu.be/tjVrpyXoi2M. Acesso em: 2 abr. 2021.

ROSTAS, M. H. S. G. Balizas suprassegmentais para a adaptação do reggae cantado em São Luís. 2010. Tese (Doutorado em Linguística e Língua Portuguesa) - Faculdade de Ciências e Letras, UNESP, Araraquara, 2010.

SILVA, T. C. Fonética e Fonologia do Português. 4. ed. São Paulo: Contexto, 2001.

SINCLAIR, D. Spice Girls Revisited. Omnibus Press, 2008. E-book.

SWAN, M. Practical English Usage: International Student's Edition. 2. ed. Oxford: Oxford University Press, 1996.

VARAH, C. Why Do 'British Singers' Such As Ed Sheeran, Adele Lose Their Accents When Singing? News Nation, 23 de setembro de 2019. Disponível em https://english.newsnationtv.com/lifestyle/others/why-do-british-singers-such-as-ed-sheeranadele-lose-their-accents-when-singing-238542.html. Acesso em: 25 mar. 2021.

\section{Sobre os autores}

André Luiz, Machado (Orcid uD: https://orcid.org/0000-0003-4901-9186)

Doutorando no Programa de Pós-Graduação em Linguística e Língua Portuguesa da Universidade Estadual Paulista (UNESP); mestre em Linguística e Língua Portuguesa; bacharel e licenciado em Letras pela mesma instituição.

Gladis Massini-Cagliari (Orcid iD: https://orcid.org/0000-0002-4050-7645)

Doutora e mestra em Linguística pela Universidade Estadual de Campinas (Unicamp); bacharela e licenciada em Letras pela mesma instituição. É professora da Universidade Estadual Paulista (UNESP). Pesquisadora 1B do CNPq.

Recebido em abril de 2021.

Aprovado em junho de 2021. 